\title{
APPLICATION OF FLIPPED LEARNING TO THE LIFE CYCLE ASSESSMENT OF A COMPOSITE PEDESTRIAN BRIDGE
}

\author{
D. Martínez-Muñoz, N. Ata-Ali, J.V. Martí, V. Yepes \\ ICITECH. Dept. Ingeniería de la Construcción y Proyectos de Ingeniería Civil. Universitat \\ Politècnica de València (SPAIN)
}

\begin{abstract}
This study describes the introduction of the life cycle assessment methodology to a postgraduate course through a flipped classroom. The analysis was carried out in the subject predictive models and optimization of concrete structures framed within the studies of the Master's Degree in Concrete Engineering. In this course, students are introduced to optimization methods through the application of algorithms, as well as other concepts, such as multi-criteria decision-making, the design of experiments and predictive and regression methods. In this case, the life cycle assessment of a $28 \mathrm{~m}$ span length steel-concrete composite pedestrian bridge was carried out. The section consists of a steel beam topped by a concrete slab. For this, computer tools were used that implement different scenarios to model the different possibilities. The database used was Ecoinvent and the software employed to assess the life cycle of the structure was openLCA, developed by Greendelta. This methodology allows the student to acquire transversal competencies, such as ethical and environmental responsibility, knowledge of contemporary problems, critical thinking and the use of specific instruments, all of them framed within the institutional project of the Universitat Politècnica de València. This work also presents future studies related to the life cycle assessment of footbridges, not only from energy and environmental points of view, but also accounting for economic and social factors. This learning process was achieved with a reverse teaching methodology that allows the student to acquire knowledge in a more efficient way.
\end{abstract}

Keywords: technological resources, tools, active methodology, flipped teaching, life cycle assessment, transversal competences.

\section{INTRODUCTION}

The Spanish education system has undergone a number changes in recent years due to the need to adapt to the European Higher Education Area (EHEA) as a consequence of the modification of the orientation of education to which countries are committed in the Bologna Declaration [1]. Due to this adaptation, the system of studies has been modified, changing the curricula of previous studies for undergraduate, masters and doctorate degrees with the European Credit Transfer System (ECTS). In addition, the change is shown in the methods of teaching. In previous curricula, the teaching model was the master class, in which the teacher transmitted the knowledge to the students through a class in which the student's participation was lower. However, the change of curricula also attempts to implement a new pedagogical philosophy that deprives the acquisition of skills and learning of the student through methods that encourage their participation and promote competitiveness, mobility and employability.

There are two fundamental points of view for transmitting knowledge to students [2]: teaching as the transmission of knowledge and teaching as an aid to learning. The first model considers that students simply receive the information, whereas the second model encourages the participation of students, so that learning is encouraged. Students assume a participatory role within the classroom [3]. In engineering, class dynamics are based on problem solving and analysis, but attempts are made to introduce deductive teaching into this type of study. A method to change this passive student tendency has been implemented in the Universitat Politècnica de València (UPV) and in the Escuela Técnica Superior de Ingenieros de Caminos, Canales y Puertos. Methods are being promoted to create an academic/professional profile of the students by encouraging the acquisition of different skills. To this end, different methods are promoted, such as "flipped teaching", where students are able to carry out their own self-evaluation through the activities planned by the subject's teacher. In this way, the student participates in the formation of his or her own knowledge. 
The EXCELCON Educational Innovation and Quality team focuses on research into applied techniques in engineering education and other fields of the construction sector. The group has carried out studies on the application of heuristic techniques in engineering education [4] and multicriteria decision-making [5]. In addition, the group made an assessment of the tools and methodologies active in the degree [6] and the assessment of transversal competences in engineering studies [7]-[9]. In addition, case studies have been carried out on the application of optimization techniques to walls [10]-[13], road vaults [14], [15], bridges [16], [17] and other applications, such as the prediction of the transfer length of prestressing strands [18]. The research group not only studies the optimization of these structures, but also carries out its life cycle assessment (LCA) [19]. These studies are carried out within the subjects Typologies and Procedures of the Constructions of the I.C. and Predictive Models and Optimization of Concrete Structures. The first corresponds to undergraduate studies in Public Works Engineering and the second to the Master's Degree in Concrete Engineering, both studies are part of the educational portfolio of the UPV. Furthermore, these studies make it possible to assess the employability of graduate students in construction management [20]-[22] and the competences in construction acquired at the graduate level [23] after having implemented these techniques in graduate studies.

In this case study, the methodology of the LCA has been introduced to the students by the flipped teaching methodology. This assessment concept not only allows students to increase their knowledge regarding the environmental evaluation of infrastructures, but also lets them acquire transversal competencies, such as ethical and environmental responsibility or knowledge of contemporary problems. Researchers have been studying the actual construction processes in order to improve and optimize their sustainability using different methodologies [24], [25]. Many studies of our research work are focused on the environmental [26] and social impact [27] of the infrastructures using the LCA to obtain a quantitative value of the impact taken into account. The LCA method is the most useful tool to obtain the implications related with the environment or the social impact of the processes through the use of databases, such as Ecoinvent [28].

\section{OBJECTIVES}

The objectives of this communication are as follows:

- Show the "flipped learning" procedure that has been used in the course Predictive Models and Optimization of Concrete Structures.

- Describe the tools used in the course to carry out the flipped learning.

- Evaluate the results of the application of these tools applied to teaching in postgraduate courses.

\section{DEVELOPMENT OF INNOVATION}

An innovation is proposed in the student's learning system. "Flipped teaching" is used to encourage the active participation of the student. Different tools and methods are used to facilitate the teaching-learning process. This study evaluates students' learning with the "flipped teaching" method, studying the student's self-evaluation and self-learning in each of the phases. The research is carried out in the subjects Predictive Models and Optimization of Concrete Structures of the Master's Degree in Concrete Engineering of the UPV.

In order to be able to evaluate each of the phases, a flipped teaching scheme is proposed. As shown in Figure 1, there are two main phases of work: outside and inside the classroom. In each of these two phases, different activities are carried out with evaluation points so that students can correct errors during the learning process. 


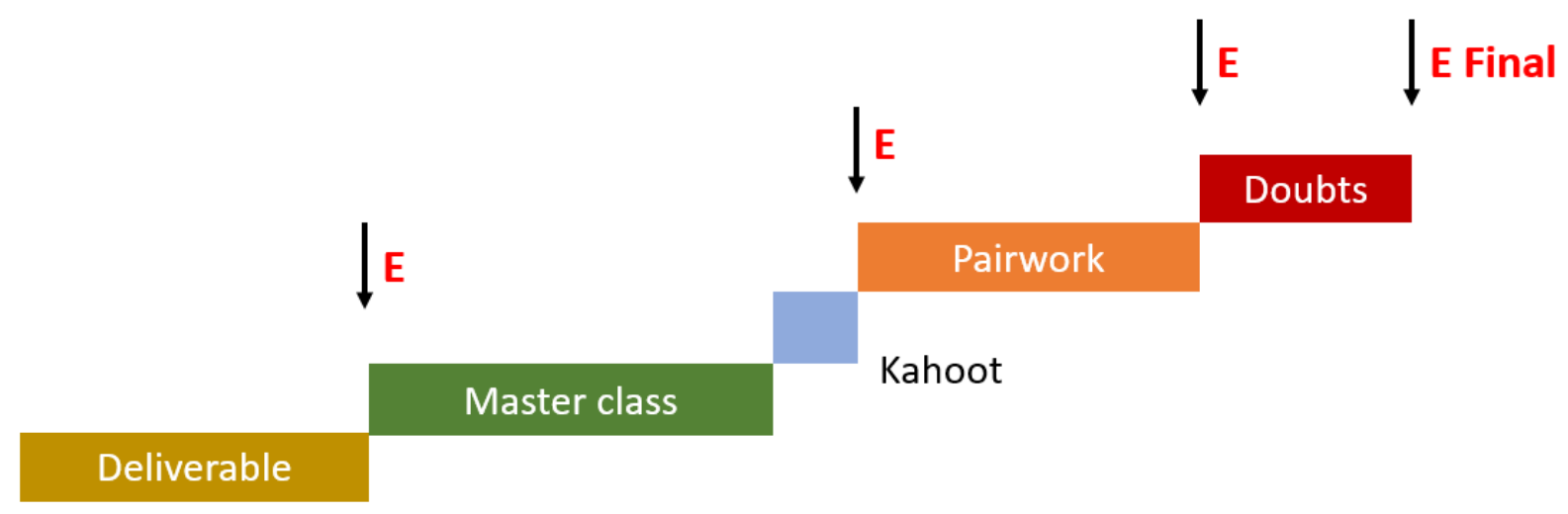

\begin{tabular}{|l|l|}
\hline Out of classroom & Classroom \\
\hline
\end{tabular}

Figure 1. Flipped learning outline

The methods and tools used during the process are described below.

\section{PoliformaT resources tool}

In the resources folder, the student has the documents and material to be able to carry out the learning. Class topics and bibliography are provided for the student to broaden their knowledge.

\section{Lessons}

The tool allows the student to know at all times the organization of the subject and the planning of each of the classes. Through the tool, the teacher provides the students all the necessary information to follow the classes, as well as the deliverables and results of all the exercises. Access conditions are created, so that students can access the different contents depending on the phase of the planning. This tool helps the application of flipped teaching.

\section{Polimedia videos}

This is a tool that allows presenting a topic by means of videos. The video consists of a presentation of a specific topic by the teacher, which is supported by a presentation with slides. These videos allow the students to stop it as many times as he or she wants to make notes or queries.

\section{Portfolio}

The portfolio is a set of documents that the student must complete. In it, all the work done during the course is collected, so that the student is able to see all the work he or she has done and carry out the evaluation process. The documents are shared with the teacher in a virtual space, so both teacher and student can observe the learning procedure followed to make the assessment.

\section{Flipped teaching}

Flipped teaching consists of turning the traditional class around, allowing the student to carry out the learning process in a more active way. The contents are introduced to the student through videos and notes posted in the PoliformaT tool or other methods. During classes, the part where the teacher explains the content to the students is drastically reduced, and the time is dedicated to different activities that allow the student to participate. The teacher becomes a guide for the student while he or she actively applies, analyzes, evaluates and creates in the classroom, while outside the classroom he or she has previously studied the subject, following Bloom's Taxonomy.

\section{Correction of deliverables}

In order to actively learn, students hand in a series of assignments prior to the start of class. In addition, in the class they redo exercises that allow the student to fix the concepts and correct possible mistakes made in previous phases. The proposed tasks can be carried out with the reading and study of the resources previously provided by the teacher. During the classes, all these activities are corrected by means of a formative evaluation. Furthermore, the teacher takes the opportunity to nuance or expand the subject. 


\section{Ecoinvent}

In order to carry out the LCA of a structure, it is necessary to use a database to evaluate the total impact of the structure. In this study, students have been introduced to the use of this type of database. Ecoinvent has a large number of processes that allow modeling and later evaluating the total impact of the activity studied. This makes it possible to make students aware of the impact of each of the processes carried out during the construction of infrastructures linked to civil engineering.

\section{OpenLCA}

In order to obtain the total value of the impact, students are provided with this software that allows, in addition to using the processes of a database such as Ecoinvent, to create new processes that provide a real recreation of the activity that will be carried out during construction. This software is provided by the company Greendelta and is free of charge.

\section{Kahoot}

This is a web tool that consists of asking questions for which there are four possible answers. The students connect to the application with their mobile devices and the application indicates if the answer is correct and you show the ranking of students according to the speed and number of correct answers.

\section{Work between pairs}

Peer-to-peer work consists of performing the life cycle environmental impact assessment exercise of the proposed composite pedestrian bridge with openLCA software and the Ecoinvent database. Students are thus able to compare different hypotheses, obtaining transversal competencies, such as critical thinking, knowledge of contemporary problems or the use of specific tools. This work is done in groups of two or three people.

\section{RESULTS}

The following is an example of the results obtained by the students in this case study. As can be seen, the program provides two approaches, a midpoint one with 18 indicators that serve to compare the results in a specific impact, such as global warming potential or the depletion of a resource, such as metal, which in this case is the most used resource due to the need for steel to manufacture the cross section. In contrast, the total impact of the structure is obtained, so we can directly compare this impact to see which of the hypotheses, from the environmental point of view, is the best.

Table 1. Recycled steel percentages.

\begin{tabular}{lccccc}
\hline Country & $\begin{array}{c}\text { Thousands } \\
\text { of tons }\end{array}$ & $\begin{array}{c}\text { \%European } \\
\text { total } \\
\text { production }\end{array}$ & \%BOF & \%EAF & \%Recycled \\
\hline Germany & 42,080 & $25.97 \%$ & $70.10 \%$ & $29.90 \%$ & $43.22 \%$ \\
Italy & 23,373 & $14.43 \%$ & $24.30 \%$ & $75.70 \%$ & $80.32 \%$ \\
France & 14,413 & $8.90 \%$ & $66.10 \%$ & $33.90 \%$ & $46.46 \%$ \\
Spain & 13,616 & $8.40 \%$ & $33.40 \%$ & $66.60 \%$ & $72.95 \%$ \\
Poland & 9,001 & $5.56 \%$ & $56.80 \%$ & $43.20 \%$ & $53.99 \%$ \\
\hline
\end{tabular}

In these results, the students make a comparison between different cities with different percentages of steel recycling in the production process. Table 1 shows the recycling percentages obtained as a function of the steel manufacturing processes obtained by the World Steel Association [29]. 


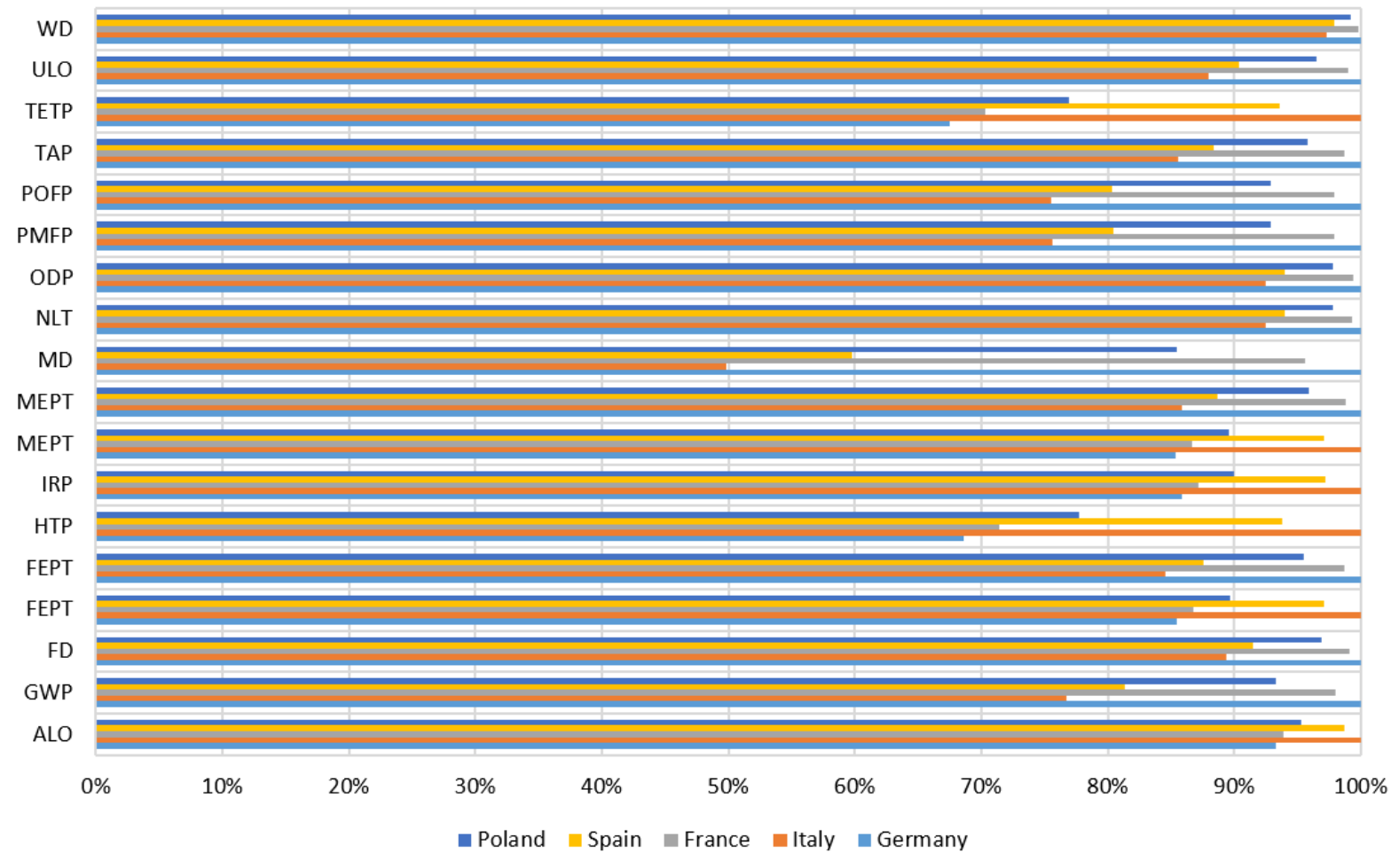

Figure 2. Impact for midpoint indicators.

As can be seen in Figure 2, the countries that have a lower recycling percentage have a greater impact on the categories that relate to the consumption of resources and the favoring of global warming. However, the countries with the highest percentage of steel recycling have an impact on other categories.

Once they have seen the results with the indicators, the students need to know the global impact, so that they can decide which of the alternatives is better from the environmental point of view. At this point, the program provides the results shown in Figure 3 and Table 2.

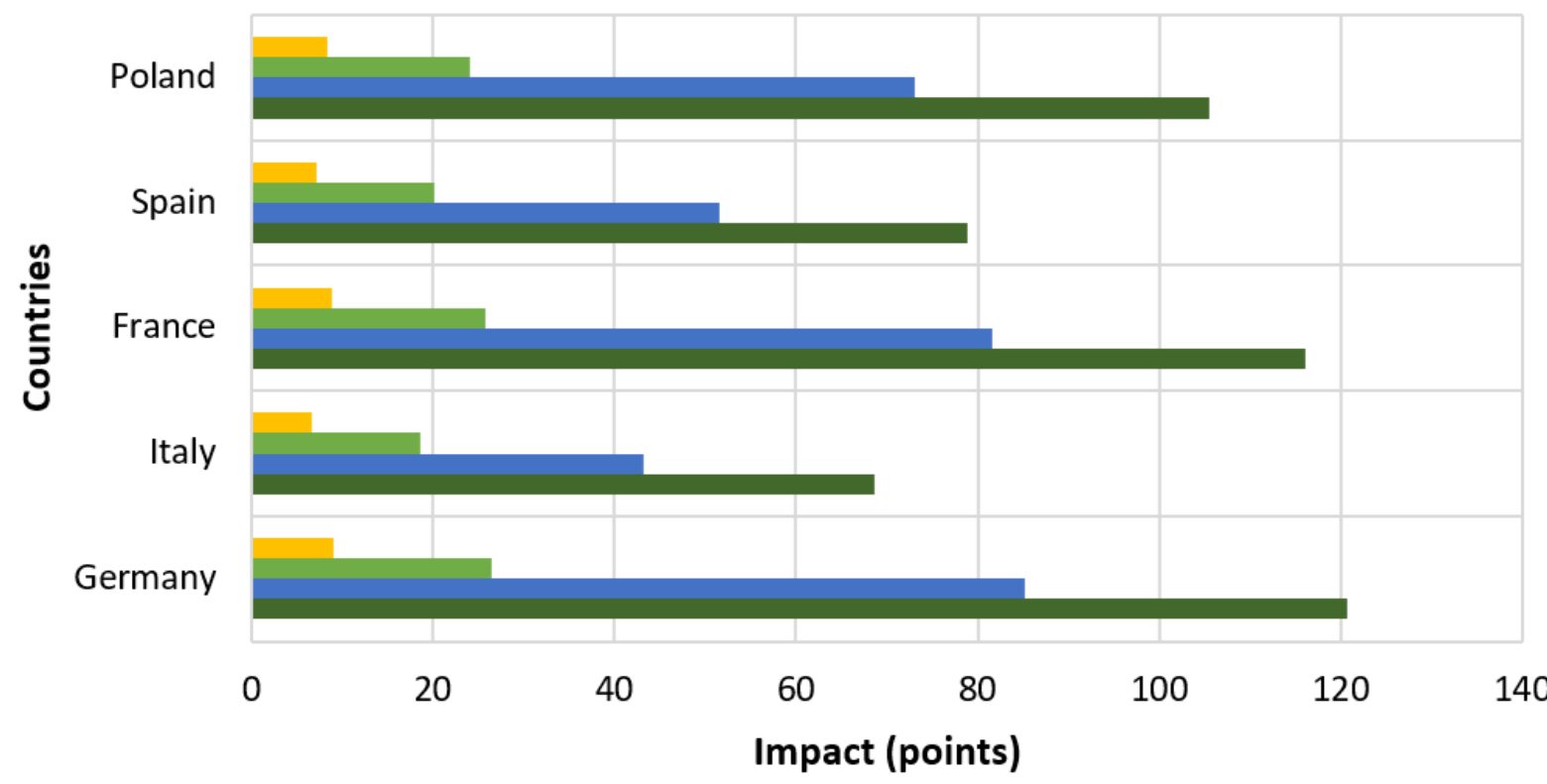

Ecosystems $\quad$ Human Health $\quad$ Resources $\quad$ Total Impact

Figure 3. Impacts for the three main indicators and total impact. 
Table 2. Percentage increase over minimum.

\begin{tabular}{lccccc}
\hline \multicolumn{1}{c}{ Country } & $\%$ Recycled & $\begin{array}{c}\Delta \text { Ecosystems } \\
\text { quality }\end{array}$ & $\begin{array}{c}\Delta \text { Human } \\
\text { Health }\end{array}$ & $\Delta$ Resources & $\begin{array}{c}\Delta \text { Total } \\
\text { impact }\end{array}$ \\
\hline Germany & $43.22 \%$ & $36.92 \%$ & $41.50 \%$ & $96.97 \%$ & $76.06 \%$ \\
Italy & $80.32 \%$ & $0.00 \%$ & $0.00 \%$ & $0.00 \%$ & $0.00 \%$ \\
France & $46.46 \%$ & $33.70 \%$ & $37.88 \%$ & $88.50 \%$ & $69.42 \%$ \\
Spain & $72.95 \%$ & $7.34 \%$ & $8.25 \%$ & $19.27 \%$ & $15.11 \%$ \\
Poland & $53.99 \%$ & $26.20 \%$ & $29.45 \%$ & $68.81 \%$ & $53.97 \%$ \\
\hline
\end{tabular}

\section{CONCLUSIONS}

This study describes the methodology used to carry out the LCA of a structure in the postgraduate course Predictive Models and Optimization of Concrete structures. The strategies, tools and specific software used during the learning process of the students have been shown as they are: the tool resources of PoliformaT, lessons, Polimedia videos, portfolio, Kahoot, openLCA, the Ecoinvent database and the proposed deliverables, in addition to the flipped teaching methodology and the correction of deliverables.

Once the exercise has been carried out, the conclusions obtained by the students are as follows:

- In a composite structure, the material that produces the most impact is steel.

- The steel manufacturing processes and the percentage of recycling have a direct influence on the total impact of the structure.

- Steel manufacturing processes have a direct impact on the consumption of raw materials.

- The difference between producing the same structure in different countries can cause the same activity to have a very different impact.

- It is necessary to seek an improve of the production processes to reduce the impact of the structures.

- The life cycle analysis tool allows for the evaluation of the impact of an activity quantitatively.

- Learning with the flipped teaching method has allowed to acquire concepts in an easier way.

This communication opens the door to future research work on learning with the flipped teaching methodology in higher studies in the field of engineering. In addition, this method allows the student to acquire transversal competences in a more effective way.

\section{ACKNOWLEDGEMENTS}

The authors acknowledge the support received from the Ministry of Economy and Business and the FEDER funding (Research Project BIA2017-85098-R) and the Universitat Politècnica de València (EXCELCON Educational Innovation and Quality Team).

\section{REFERENCES}

[1] European Ministers of Education, "The Bologna Declaration," Retrieved June, 1999.

[2] D. Kember, K. P. Kwan, and J. Ledesma, "Conceptions of good teaching and how they influence the way adults and school leavers are taught," Int. J. Lifelong Educ., vol. 20, no. 5, pp. 393-404, 2001.

[3] L. Kane, "Educators, learners and active learning methodologies," Int. J. Lifelong Educ., vol. 23, no. 3, pp. 275-286, 2004.

[4] I. J. Navarro, V. Yepes, and J. V. Martí, "Heuristics in engineering education. A case study application to sustainable bridge management systems," in Proceedings of ICERI2018, the 11th annual International Conference of Education, Research and Innovation, Seville (Spain), 12th14th November, 2018, pp. 9788-9797. 
[5] I. J. Navarro, J. V. Martí, and V. Yepes, "Multi-criteria decision making techniques in civil engineering education for sustainability," in Proceedings of ICERI2018, the 11th annual International Conference of Education, Research and Innovation, Seville (Spain), 12th-14th November, 2018, pp. 9798-9807.

[6] E. Pellicer, L. A. Sierra, and V. Yepes, "Appraisal of infrastructure sustainability by graduate students using an active-learning method," J. Clean. Prod., vol. 113, pp. 884-896, 2016.

[7] V. Yepes, J. V. Martí, and T. García-Segura, "Desarrollo y evaluación de la competencia transversal 'pensamiento crítico' en el grado de ingeniería civil," in Jornadas de Innovación Educativa y Docencia en Red IN-RED 2016. 7-8 de julio, Valencia, 2016, pp. 1-14.

[8] V. Yepes, J. V. Martí, and F. Molina-Moreno, "Transverse competence 'critical thinking' in civil engineering graduate studies: preliminary assessment," in 11th annual International Technology, Education and Development Conference (INTED 2017), Valencia, 6th, 7th and 8th of March, 2017, pp. 2639-2649.

[9] T. García-Segura, V. Yepes, F. Molina-Moreno, and J. V. Martí, "Assessment of transverse and specific competences in civil engineering studies: 'Critical thinking," in 11th annual International Technology, Education and Development Conference (INTED 2017), Valencia, 6th, 7th and 8th of March, 2017, pp. 3683-3692.

[10] V. Yepes, F. Gonzalez-Vidosa, J. Alcala, and P. Villalba, "CO2-Optimization Design of Reinforced Concrete Retaining Walls Based on a VNS-Threshold Acceptance Strategy," J. Comput. Civ. Eng., vol. 26, no. 3, pp. 378-386, 2012.

[11] F. Molina-Moreno, J. V. Martí, and V. Yepes, "Carbon embodied optimization for buttressed earthretaining walls: Implications for low-carbon conceptual designs," J. Clean. Prod., vol. 164, pp. 872-884, 2017.

[12] V. Yepes, J. Alcala, C. Perea, and F. González-Vidosa, "A parametric study of optimum earthretaining walls by simulated annealing," Eng. Struct., vol. 30, no. 3, pp. 821-830, 2008.

[13] F. Molina-Moreno, T. García-Segura, J. V. Martí, and V. Yepes, "Optimization of buttressed earthretaining walls using hybrid harmony search algorithms," Eng. Struct., vol. 134, pp. 205-216, 2017.

[14] A. Carbonell, F. González-Vidosa, and V. Yepes, "Design of reinforced concrete road vaults by heuristic optimization," Adv. Eng. Softw., vol. 42, no. 4, pp. 151-159, 2011.

[15] A. Carbonell, V. Yepes, and F. González-Vidosa, "Automatic design of concrete vaults using iterated local search and extreme value estimation," Lat. Am. J. Solids Struct., vol. 9, no. 6, pp. 675-689, 2012.

[16] V. Penadés-plà, T. García-segura, and V. Yepes, "Accelerated optimization method for lowembodied energy concrete box- girder bridge design," Eng. Struct., vol. 179, no. June 2018, pp. 556-565, 2019.

[17] V. Yepes, M. Dasí-Gil, D. Martínez-Muñoz, V. J. López-Desfilis, and J. V. Martí, "Heuristic Techniques for the Design of Steel-Concrete Composite Pedestrian Bridges," Appl. Sci., vol. 9, no. 16, p. 3253, 2019.

[18] J. R. Martí-Vargas, F. J. Ferri, and V. Yepes, "Prediction of the transfer length of prestressing strands with neural networks," Comput. Concr., vol. 12, no. 2, pp. 187-209, 2013.

[19] P. Zastrow, F. Molina-Moreno, T. García-Segura, J. V. Martí, and V. Yepes, "Life cycle assessment of cost-optimized buttress earth-retaining walls: A parametric study," J. Clean. Prod., vol. 140, pp. 1037-1048, 2017.

[20] C. Torres-Machí, A. Carrión, V. Yepes, and E. Pellicer, "Employability of Graduate Students in Construction Management," J. Prof. Issues Eng. Educ. Pract., vol. 139, no. 2, pp. 163-170, 2013.

[21] E. Pellicer, C. Luis Correa, V. Yepes, and L. Fernando Alarcon, "Organizational Improvement Through Standardization of the Innovation Process in Construction Firms," Emj-Engineering Manag. J., vol. 24, no. 2, pp. 40-53, 2012.

[22] E. Pellicer, M. Asce, V. Yepes, C. L. Correa, L. F. Alarcón, and A. M. Asce, "Model for Systematic Innovation in Construction Companies," pp. 1-8, 2014. 
[23] V. Yepes, E. Pellicer, and A. J. Ortega, "Designing a Benchmark Indicator for Managerial Competences in Construction at the Graduate Level," J. Prof. Issues Eng. Educ. Pract., vol. 138, no. 1, pp. 48-54, 2012.

[24] A. Serpell, J. Kort, and S. Vera, "Awareness, actions, drivers and barriers of sustainable construction in chile," Technol. Econ. Dev. Econ., vol. 19, no. 2, pp. 272-288, 2013.

[25] N. Yusof, N. Zainul Abidin, S. H. M. Zailani, K. Govindan, and M. Iranmanesh, "Linking the environmental practice of construction firms and the environmental behaviour of practitioners in construction projects," J. Clean. Prod., vol. 121, pp. 64-71, 2016.

[26] J. J. Pons, V. Penadés-Plà, V. Yepes, and J. V. Martí, "Life cycle assessment of earth-retaining walls: An environmental comparison," J. Clean. Prod., vol. 192, pp. 411-420, Aug. 2018.

[27] L. A. Sierra, E. Pellicer, and V. Yepes, "Social Sustainability in the Lifecycle of Chilean Public Infrastructure," J. Constr. Eng. Manag., vol. 142, no. 5, p. 05015020, 2016.

[28] R. Frischknecht and G. Rebitzer, "The ecoinvent database system: A comprehensive web-based LCA database," J. Clean. Prod., no. 13-14, pp. 1337-1343, 2005.

[29] World Steel Association, "Steel Statistical Yearbook 2018," World Steel Assoc., 2018. 